Supporting Information

\title{
Ultrathin Two-Dimensional Membranes Assembled by lonic Covalent Organic Nanosheets with Reduced Apertures for Gas Separation
}

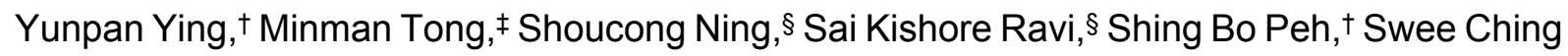
Tan,§ Stephen John Pennycook, $\S$ and Dan Zhao*,†

tDepartment of Chemical and Biomolecular Engineering, National University of Singapore, 4 Engineering Drive 4, Singapore 117585, Singapore

¥School of Chemistry and Materials Science, Jiangsu Normal University, No. 101 of Shanghai Road, Xuzhou 221116, China

§Department of Materials Science and Engineering, National University of Singapore, 9 Engineering Drive 1, Singapore 117575, Singapore

*E-mail: chezhao@,nus.edu.sg 


\section{Table of Contents}

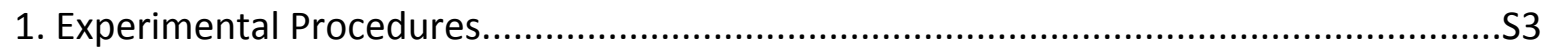

2. Supplementary Characterization and Performance Data...........................................S6

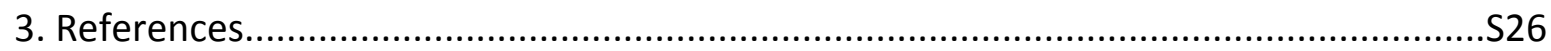




\section{Experimental Procedures}

\section{Materials}

1,3,5-Triformylphloroglucinol (Tp) was purchased from Hangzhou Yuhao Chemical Technology Co., Ltd, China. Ethidium bromide $(\mathrm{EBr})$ and 2,5-diaminobenzenesulfonic acid $\left(\mathrm{Pa}-\mathrm{SO}_{3} \mathrm{H}\right)$ were purchased from SigmaAldrich. P-toluenesulfonic acid monohydrate $\left(\mathrm{PTSA} \cdot \mathrm{H}_{2} \mathrm{O}\right)$ and trifluoroacetic acid $\left(\mathrm{CF}_{3} \mathrm{COOH}\right)$ were purchased from Tokyo Chemical Industry Co., Ltd. Toluene (AR), tetrahydrofuran (THF, AR), and ethanol (AR) were purchased from Fisher Scientific. Sodium hydroxide $(\mathrm{NaOH})$ was purchased from Sinopharm chemical reagent Co., Ltd., China. The deionized water produced by Millipore-Q System (Millipore, Billerica, MA, USA) was used in all experiments. Polytetrafluoroethylene dish (PTFE, $6 \mathrm{~cm}$ in diameter) was offered by Latech Scientific Supply Pte. Ltd, Sigapore. $\mathrm{H}_{2}$ (> 99.999\%), $\mathrm{CO}_{2}$ (> 99.999\%), $\mathrm{N}_{2}$ (>99.999\%), $\mathrm{CH}_{4}(>99.999 \%)$, and $\operatorname{Ar}(>99.999 \%)$ were purchased from Air Liquide in Singapore. Porous asymmetric $\alpha-\mathrm{Al}_{2} \mathrm{O}_{3}$ supports $\left(\gamma-\mathrm{Al}_{2} \mathrm{O}_{3}\right.$ on top) with a top pore size of $70 \mathrm{~nm}$, diameter of $25 \mathrm{~mm}$ and a thickness of $1 \mathrm{~mm}$ were purchased from Fraunhofer Institut für Keramische Technologien and Systeme (IKTS).

\section{Synthesis of $\mathrm{Pa}-\mathrm{SO}_{3} \mathrm{Na}$}

Equal molar $\mathrm{Pa}_{-} \mathrm{SO}_{3} \mathrm{H}$ and $\mathrm{NaOH}$ were successively added into a round-bottom flask $(100 \mathrm{~mL})$ containing 30 $\mathrm{mL}$ of deionized water. The mixture was stirred for about 1 hour. Then rotary evaporation was conducted to remove water and the product was collected (yield: $99 \%)$.

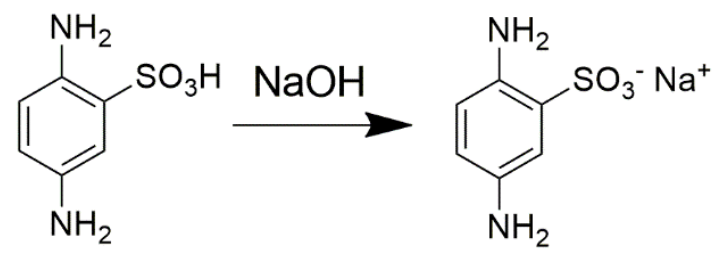

Figure S1. Synthesis of $\mathrm{Pa}-\mathrm{SO}_{3} \mathrm{Na}$.

Characterizations. The morphologies of iCONs and membranes were investigated by field emission scanning electron microscopy (FESEM, JSM-6700, JEOL) under $20 \mathrm{kV}$. Before observation, all samples were sputtered with Pt by Sputter Coater (Cressington 208 HR) under a current of 20 mA for 120 s. Transmission electron microscopy (TEM) and selected area electron diffraction (SEAD) of samples on a carbon-coated TEM grid were conducted on a JEOL JEM-3010 transmission electron microscope. Atomic force microscopy (AFM) of the nanosheets deposited 
on silica wafers was conducted using tapping mode with a Bruker Dimension Icon atomic force microscope. Attenuated Total Reflectance-Flourier transformed infrared (ATR-FTIR) spectra were obtained with a VERTEX 70 FTIR spectrometer (Bruker). The surface charge properties were analyzed by a SurPASS Electrokinetic Analyzer (Anton Paar). Thermogravimetric analyses (TGA) were performed using a thermogravimetric analyser instrument (Shimadzu DTG-60AH) in the temperature range of $20-800{ }^{\circ} \mathrm{C}$ with a heating rate of $5{ }^{\circ} \mathrm{C} \mathrm{min}-1$ under flowing $\mathrm{N}_{2}$ atmosphere $\left(50 \mathrm{~mL} \mathrm{~min}^{-1}\right)$. The crystallinity of samples was characterized by X-ray diffraction (XRD) on an X-ray powder diffractometer (Rigaku MiniFlex 600) equipped with a Cu sealed tube $(\lambda=1.5418 \AA$ ) at a scan rate of 0.5 ${ }^{\circ} \min ^{-1}$.

Gas separation tests. Both single gas permeation and mixed gas separation performance were tested using a home-made Wicke-Kallenbach gas permeation apparatus described previously. ${ }^{1}$ The membrane was fixed and sealed in the permeation cell. The permeation cell containing membrane was placed in a furnace to control the test temperature. The volumetric gas flow rates were controlled by mass flow controllers (MFC, D07-26C, SevenStar, China). The membranes were measured under dry or humidified conditions. In the separation tests with humid feed gases (relative humidity is $85 \%$ ), the feed gases were saturated with water vapour by flowing through a pure water tank prior to the membrane permeation cell. Argon was adopted as the sweep gas at a

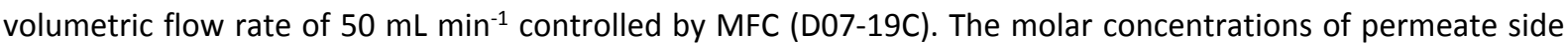
gases were analysed by gas chromatograph (GC-2014, Shimadzu) with two TCD detectors. The permeation data were recorded at steady state when the composition concentrations of permeate side gas analysed by GC were constant. Every data point was tested at least 3 times to ensure the reproducibility.

For single gas permeation test, the gas test sequence was $\mathrm{H}_{2}, \mathrm{~N}_{2}, \mathrm{CH}_{4}$ and then $\mathrm{CO}_{2}$. The purpose is to avoid the adsorption interaction of $\mathrm{CH}_{4}$ and $\mathrm{CO}_{2}$ on $\mathrm{H}_{2}$ and $\mathrm{N}_{2}$ permeation. The volumetric flow rate was set at $50 \mathrm{~mL}$ $\min ^{-1}$. The gas permeance $\left(P_{i}, \mathrm{GPU}\right)$ of component gas $i$ was calculated using equation $\mathrm{S} 1$,

$P_{i}=\frac{N_{i}}{3.348 \times 10^{-10} \cdot A \cdot \Delta P_{i}}$

where $N_{i}$ is the molar flow rate of gas $i$ at standard temperature and pressure (STP) (mol s-1), $A$ is the membrane effective area $\left(\mathrm{m}^{2}\right)$, and $\Delta P_{i}$ is the partial pressure difference of component $i(\mathrm{~Pa})$.

When considering the thickness effect on the permeance, the permeance was converted into permeability using equation S2, 
$P_{i}=\frac{10^{16}}{3.348} \cdot \frac{N_{i} \cdot l}{A \cdot \Delta P_{i}}$

where $/$ is the membrane thickness $(\mathrm{m})$.

The ideal selectivity (IS) of gas pair i/j was calculated using equation S3,

$\mathrm{IS}=\frac{P_{i}}{P_{j}}$

where $P_{i}$ and $P_{j}$ are the permeability or permeance of gas $i$ and gas $j$, respectively.

In mixed gas separation test, the feed volumetric flow rates of both gases were set at $25 \mathrm{~mL} \mathrm{~min}^{-1}$. Meanwhile, the high flow rates were used to ensure the membrane stage cut (denoted as the fraction of feed gas that permeates the membrane) is below $1 \%$. The gas permeance or permeability was calculated similarly as in single gas calculations. Separation factor $(\alpha)$ of gas pair $\mathrm{i} / \mathrm{j}$ was calculated using equation $\mathrm{S} 4$,

$$
\alpha_{i / j}=\frac{y_{i} / y_{j}}{x_{i} / x_{j}}
$$

where $y_{i} / y_{j}$ and $x_{i} / x_{j}$ represent the gas molar concentration ratios in permeate and feed side, respectively. 
(a)

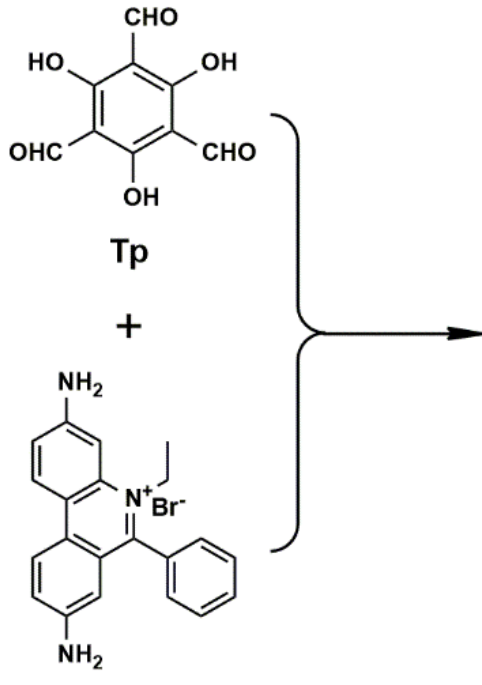

$\mathrm{EBr}$

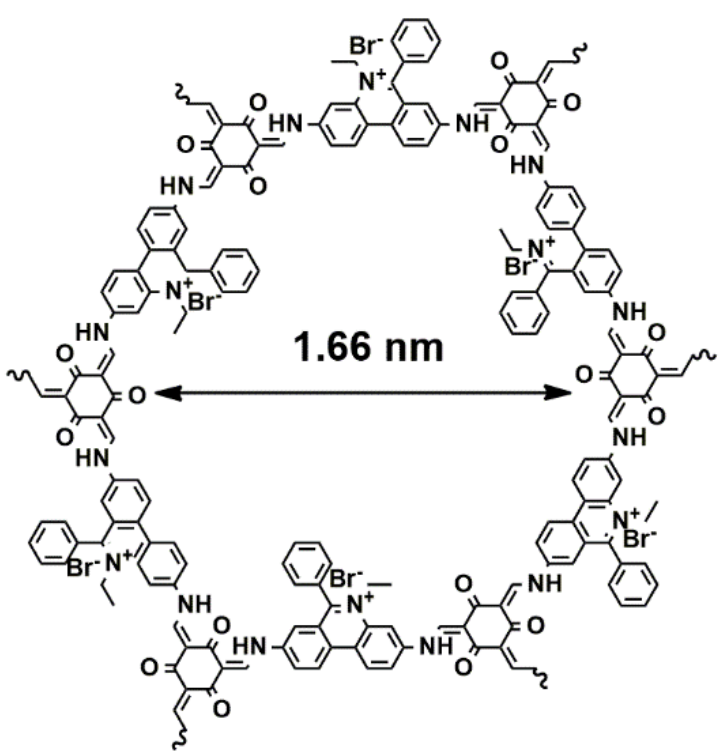

Cationic TpEBr

(b)

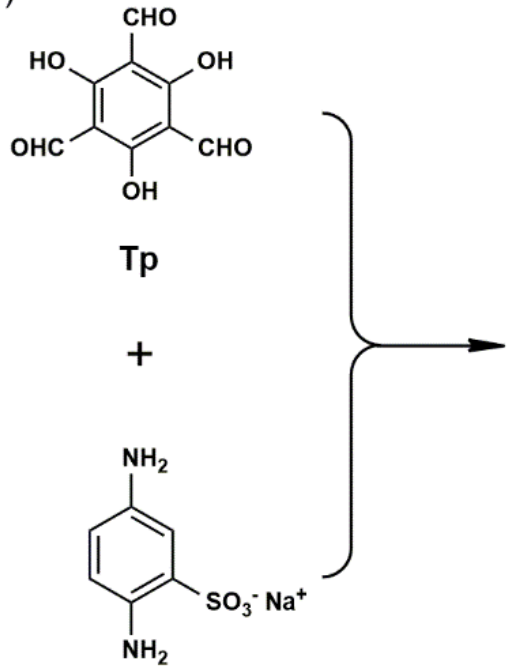

$\mathrm{Pa}-\mathrm{SO}_{3} \mathrm{Na}$

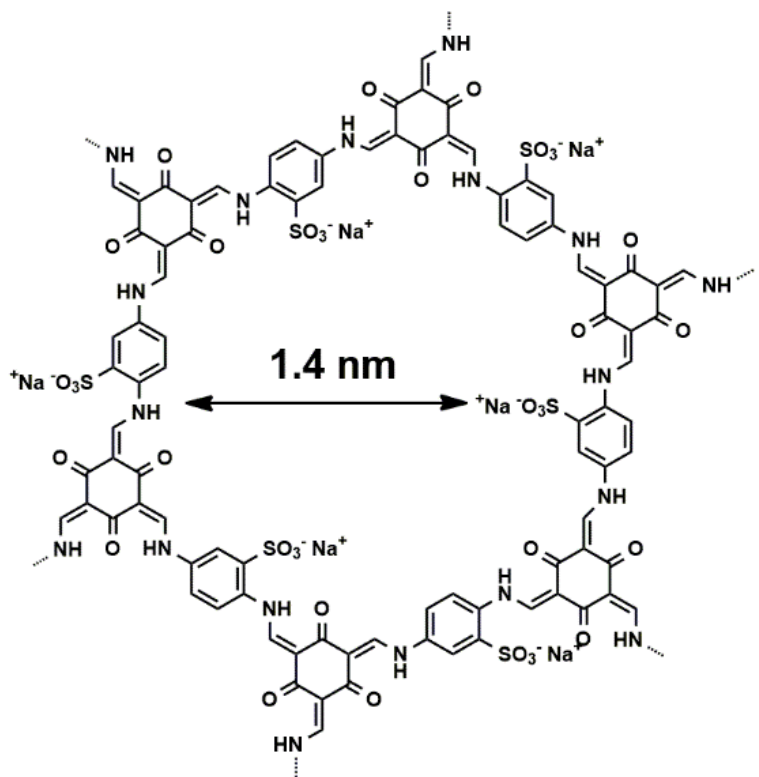

Anionic $\mathrm{TpPa}-\mathrm{SO}_{3} \mathrm{Na}$

Figure S2. Schematic representation of the synthesis of (a) cationic $\mathrm{TpEBr}$ and (b) anionic $\mathrm{TpPa}-\mathrm{SO}_{3} \mathrm{Na}$. 


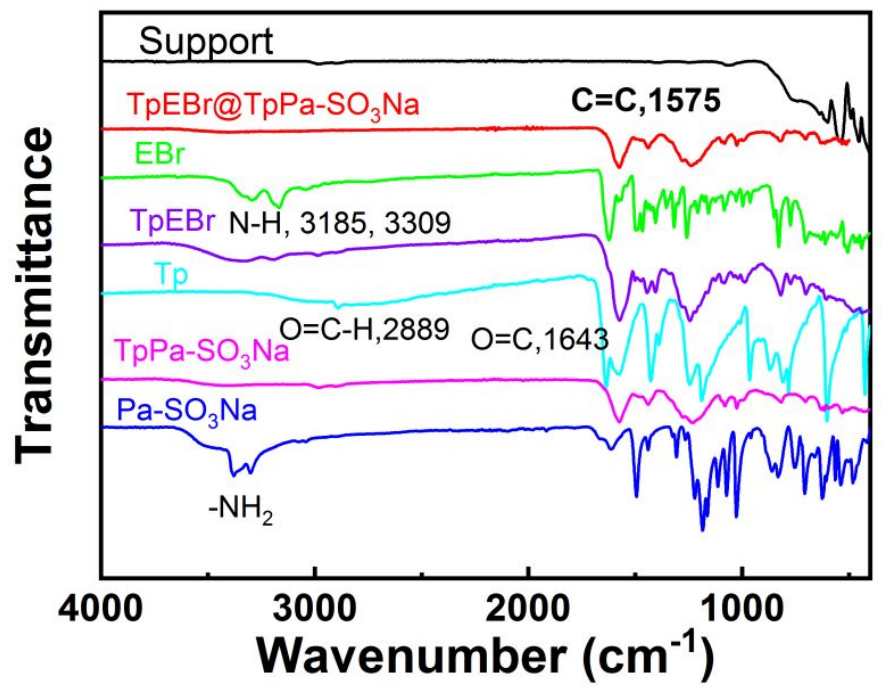

Figure S3. FT-IR spectra of $\mathrm{TpEBr}$ iCONs, $\mathrm{TpPa}-\mathrm{SO}_{3} \mathrm{Na}$ iCONs, monomers, and $\mathrm{TpEBr} @ \mathrm{TpPa}-\mathrm{SO}_{3} \mathrm{Na}$ nanosheet membranes. 


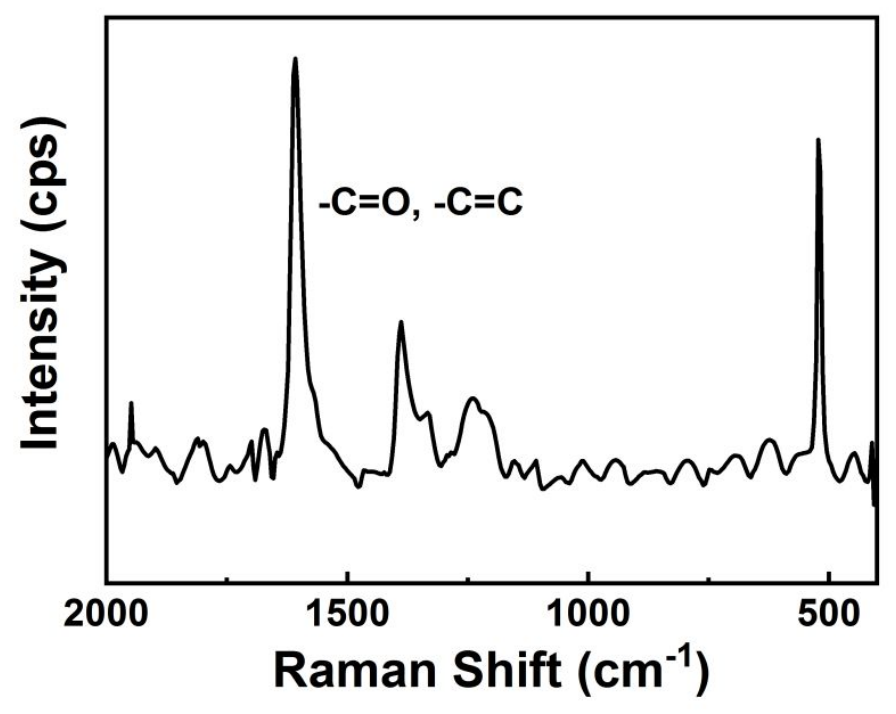

Figure S4. Raman spectrum of $\mathrm{TpEBr}$ nanosheets.

Note: The band in the range of $1610-1550 \mathrm{~cm}^{-1}$ corresponds to the $-\mathrm{C}=\mathrm{O}$ and $-\mathrm{C}=\mathrm{C}$ groups, also indicating the formation of $\beta$ - ketoenamine linkages in the iCONs. 


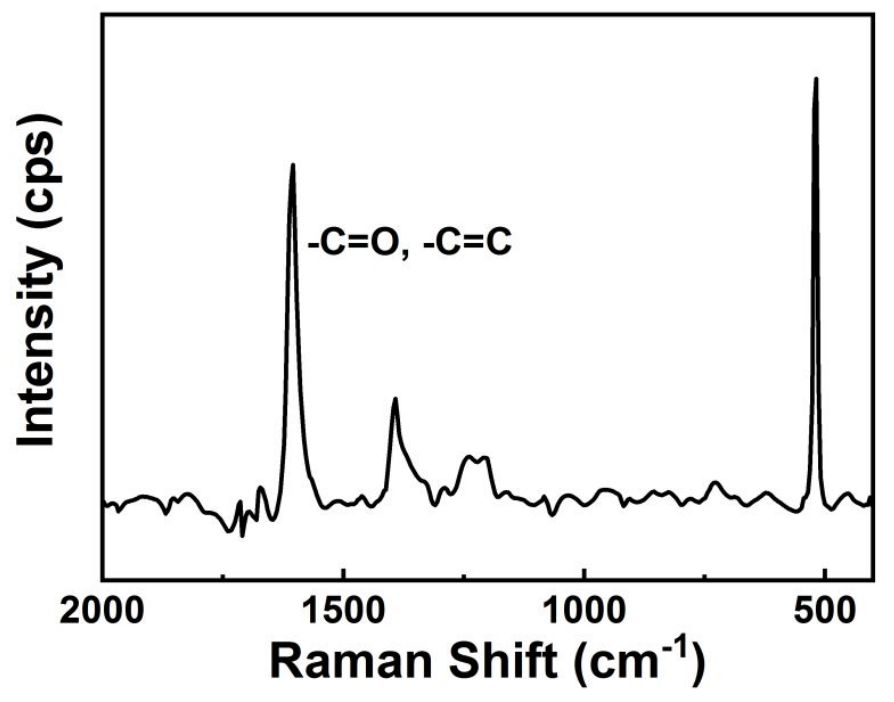

Figure S5. Raman spectrum of $\mathrm{TpPa}-\mathrm{SO}_{3} \mathrm{Na}$ nanosheets.

Note: The band in the range of $1610-1550 \mathrm{~cm}^{-1}$ corresponds to the $-\mathrm{C}=\mathrm{O}$ and $-\mathrm{C}=\mathrm{C}$ groups, also indicating the formation of $\beta$ - ketoenamine linkages in the iCONs. 

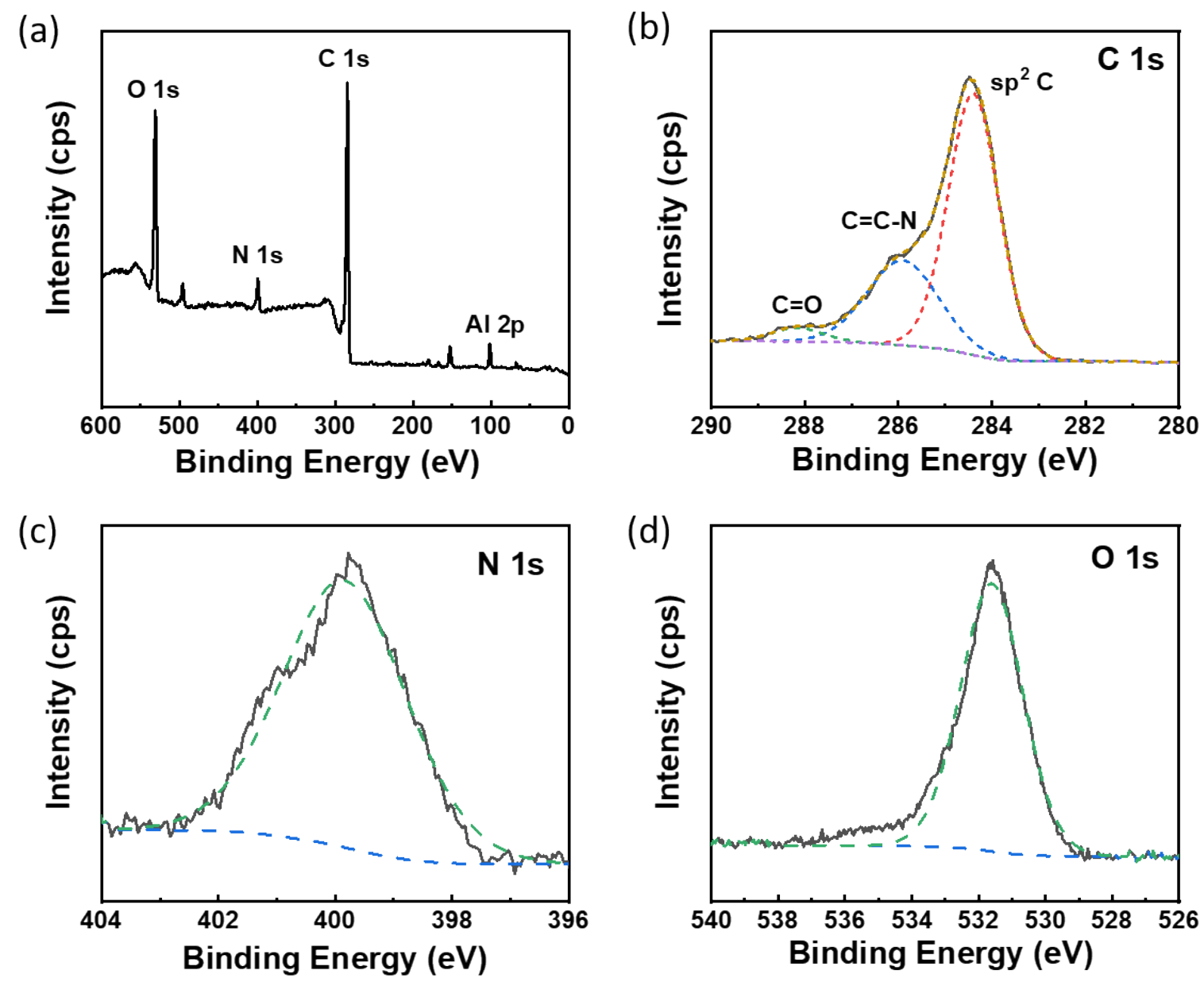

Figure S6. (a) A typical XPS survey spectrum of the TpEBr nanosheets. (b-d) High resolution XPS spectra of C 1s, $\mathrm{N} 1 \mathrm{~s}$, and $\mathrm{O} 1 \mathrm{~s}$.

Note: In the complete survey XPS plots of TpEBr iCONs, three intense peaks were observed in the spectra, which represent $\mathrm{C} 1 \mathrm{~s}, \mathrm{O} 1 \mathrm{~s}$, and $\mathrm{N} 1 \mathrm{~s}$ signals, respectively. In the high-resolution spectrum of $\mathrm{C} 1 \mathrm{~s}$, the two signals at $286 \mathrm{eV}$ are for $\mathrm{C}=\mathrm{C}$ or $\mathrm{C}-\mathrm{C}$, and the broad signal in the range $288 \mathrm{eV}$ was assigned to $\mathrm{C}-\mathrm{O}$ or $\mathrm{C}=\mathrm{O}$. Therefore, the signal at $286 \mathrm{eV}$ could be ascribed to the $\mathrm{C}=\mathrm{C}$ double bonds or $\mathrm{C}-\mathrm{C}$ bond present in the framework of 2D iCONs. The high-resolution N 1s spectrum displays only one strong signal at $399.8 \mathrm{eV}$, which corresponds to the enamine nitrogen $(\mathrm{C}=\mathrm{C}-\mathrm{NH}-)$ in the occurrence of the imine-enamine tautomerism process during the condensation reaction. Moreover, the signal at about $531.5 \mathrm{eV}$ could be attributed to the $\mathrm{C}=\mathrm{O}$ bond, as displayed in the high resolution spectrum of $\mathrm{O} 1 \mathrm{~s}$. 
(a)

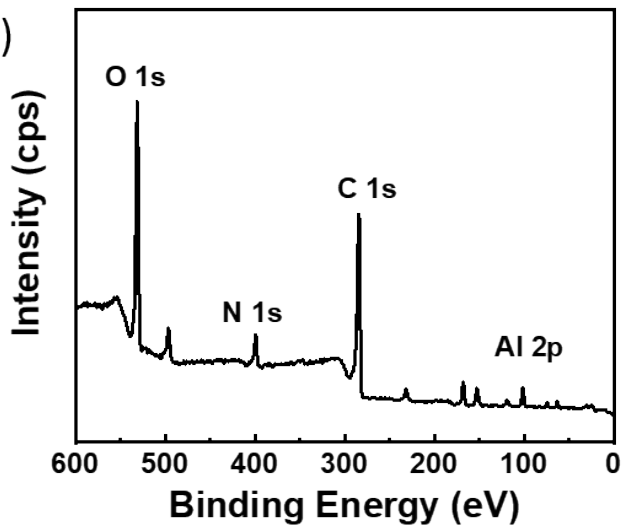

(c)

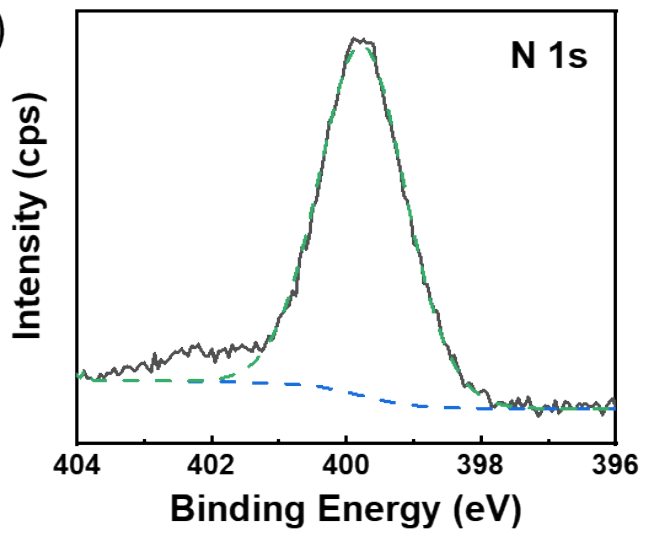

(b)

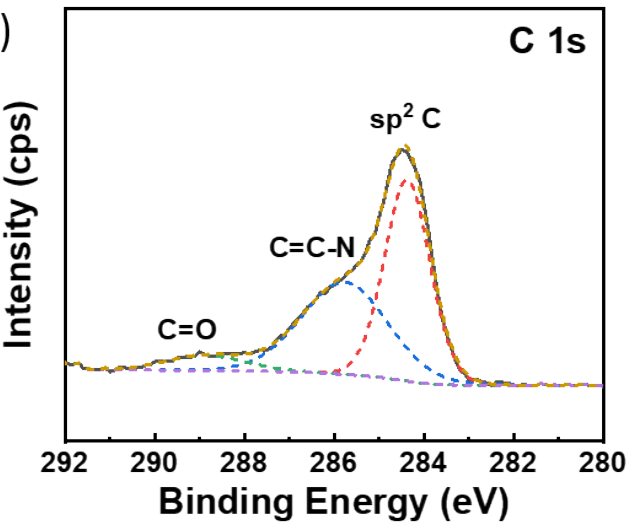

(d)

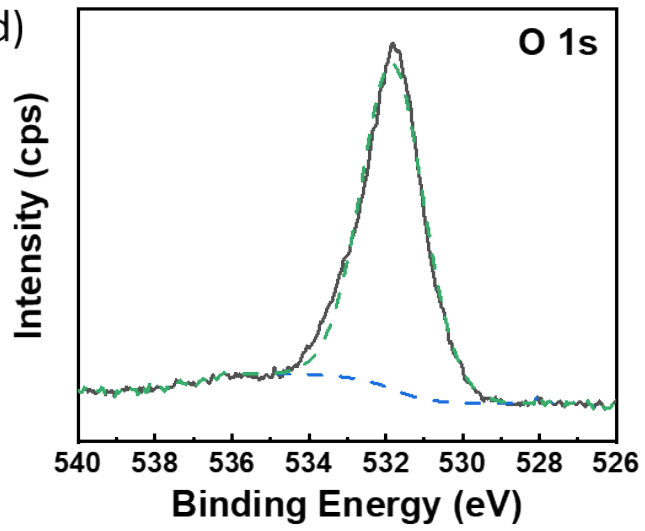

Figure S7. (a) A typical XPS survey spectrum of the $\mathrm{TpPa}_{-} \mathrm{SO}_{3} \mathrm{Na}$ nanosheets. (b-d) High resolution XPS spectra of C $1 \mathrm{~s}, \mathrm{~N} 1 \mathrm{~s}$, and $\mathrm{O} 1 \mathrm{~s}$.

Note: In the complete survey XPS plots of $\mathrm{TpPa}-\mathrm{SO}_{3} \mathrm{Na}$ iCONs, three intense peaks were observed in the spectra, which represent $\mathrm{C} 1 \mathrm{~s}, \mathrm{O} 1 \mathrm{~s}$, and $\mathrm{N} 1 \mathrm{~s}$ signals, respectively. In the high-resolution spectrum of $\mathrm{C} 1 \mathrm{~s}$, the two signals at $286 \mathrm{eV}$ are for $\mathrm{C}=\mathrm{C}$ or $\mathrm{C}-\mathrm{C}$, and the broad signal in the range $289 \mathrm{eV}$ was assigned to $\mathrm{C}-\mathrm{O}$ or $\mathrm{C}=\mathrm{O}$. Therefore, the signal at $286 \mathrm{eV}$ could be ascribed to the $\mathrm{C}=\mathrm{C}$ double bonds or $\mathrm{C}-\mathrm{C}$ bond present in the framework of $2 \mathrm{D}$ iCONs. The high-resolution N 1s spectrum displays only one strong signal at $399.8 \mathrm{eV}$, which corresponds to the enamine nitrogen $(\mathrm{C}=\mathrm{C}-\mathrm{NH}-)$ in the occurrence of the imine-enamine tautomerism process during the condensation reaction. Moreover, the signal at about $531.5 \mathrm{eV}$ could be attributed to the $\mathrm{C}=\mathrm{O}$ bond, as displayed in the high resolution spectrum of 01 s. 


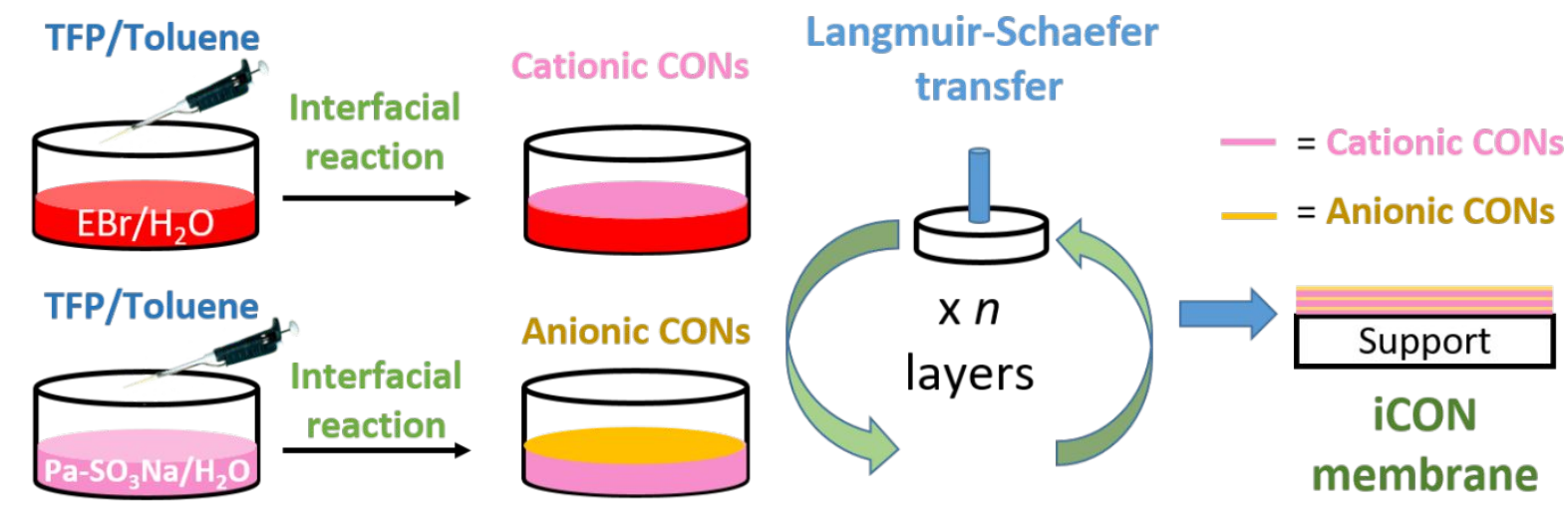

Figure S8. Scheme of the Layer-by-Layer assembly of TpEBr@TpPa-SO ${ }_{3} \mathrm{Na}$ iCON membranes using a LangmuirSchaefer transfer method. 

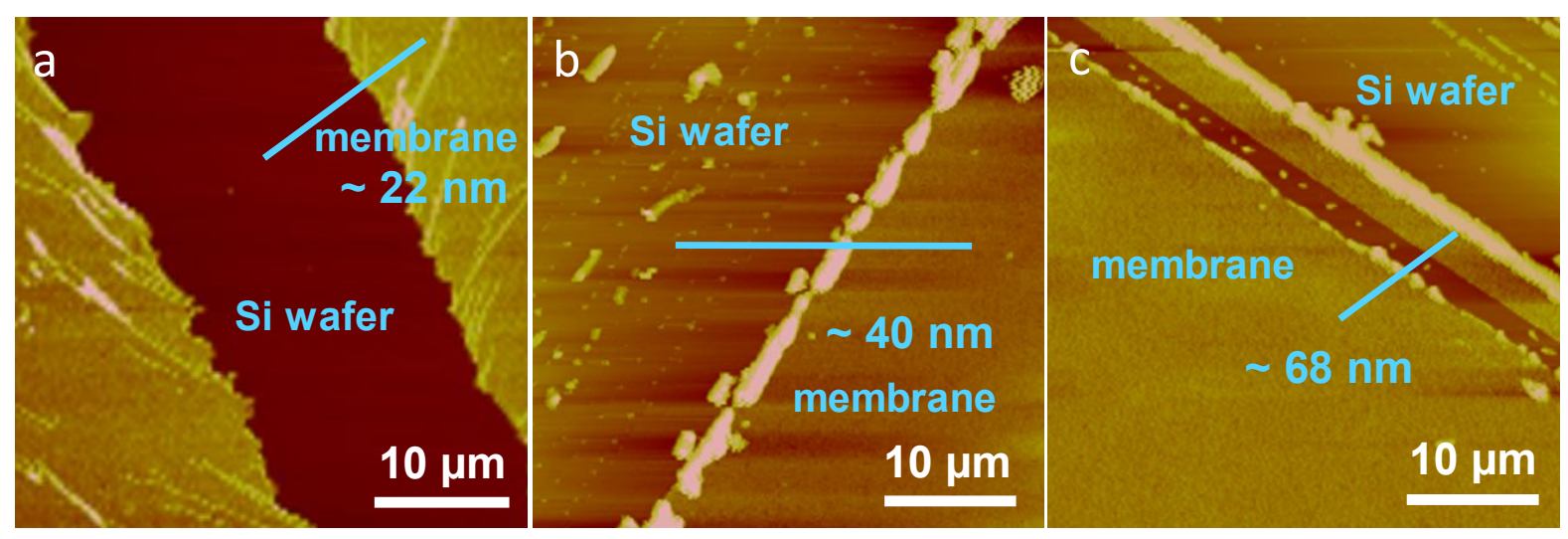

Figure S9. Membrane thicknesses determined by AFM.

Note: The membrane samples with different thicknesses were fabricated on Si wafer using the same method as on porous $\mathrm{Al}_{2} \mathrm{O}_{3}$ support. Before conducting thickness determination by $A F M$, a needle was used to create scratches on the membrane surface. 


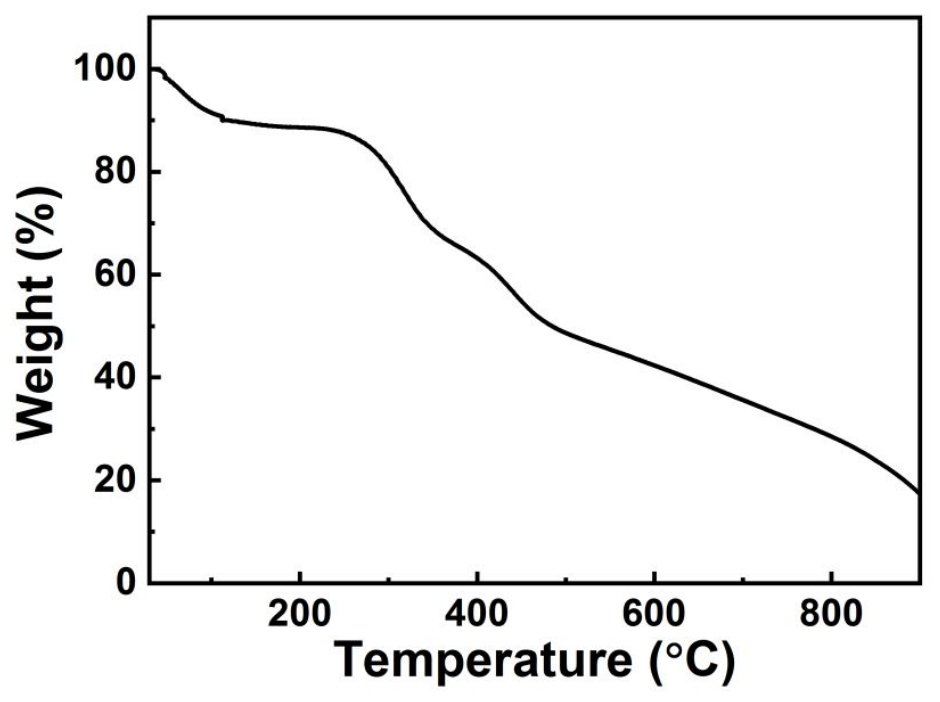

Figure S10. TGA curve of TpEBr@TpPa-SO ${ }_{3} \mathrm{Na}$ iCON membrane.

Note: The weight loss before $100{ }^{\circ} \mathrm{C}$ in the TGA curve can actually be ascribed to the removal of physically adsorbed water in iCONs. Because of the ionic feature of the iCONs, they tend to adsorb substantial amounts of water from the air. The hybrid iCON membranes are thermally stable up to ca. $260{ }^{\circ} \mathrm{C}$, which guarantees their applications under high temperatures. This result is consistent with the previous report. ${ }^{2}$ 


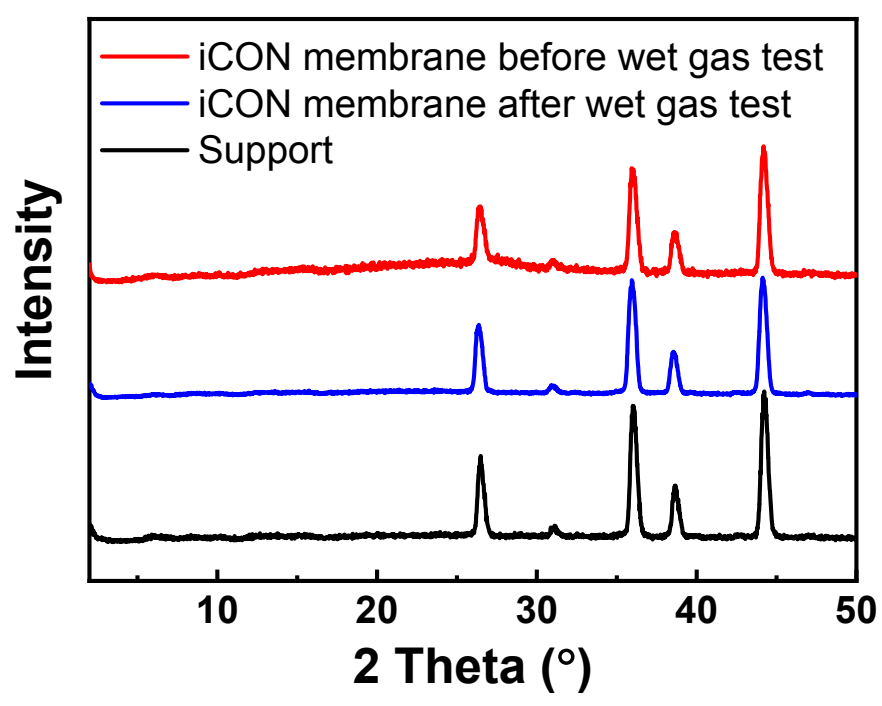

Figure S11. PXRD patterns of the bare $\mathrm{Al}_{2} \mathrm{O}_{3}$ support and the assembled TpEBr@TpPa-SO $\mathrm{Na}_{3}$ iCON membrane before and after gas separation test.

Note: Because of the ultrathin thickness of the iCON membrane, powder X-ray diffraction (PXRD) was not sensitive enough to give crystallinity information on the membrane sample. According to Dichtel et al., it was not possible to confirm the crystallinity of the COF thin films using PXRD when the thickness is less than $100 \mu \mathrm{m} .^{3}$ In an attempt to elucidate the diffraction peaks, we prepared thicker membranes on the $\mathrm{Al}_{2} \mathrm{O}_{3}$ support. Despite this effort, XRD analyses of samples yielded patterns nearly identical to those of the pristine $\mathrm{Al}_{2} \mathrm{O}_{3}$ support. This phenomenon was also observed in some other studies. ${ }^{4}$ 


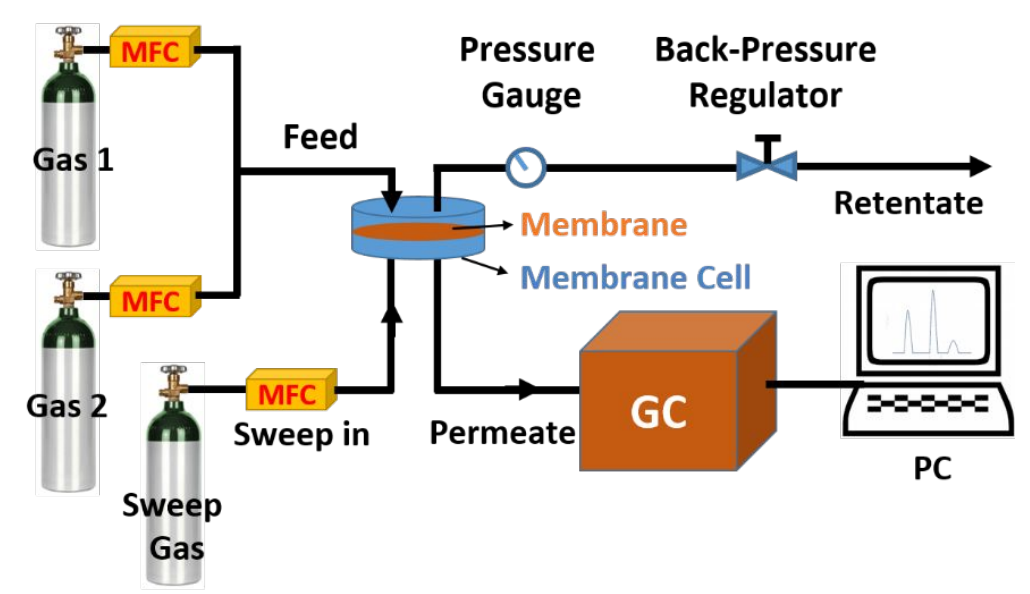

MFC: mass flow controller GC: gas chromatograph

PC: personal computer

Figure S12. Scheme of the home-built Wicke-Kallenbach setup. 


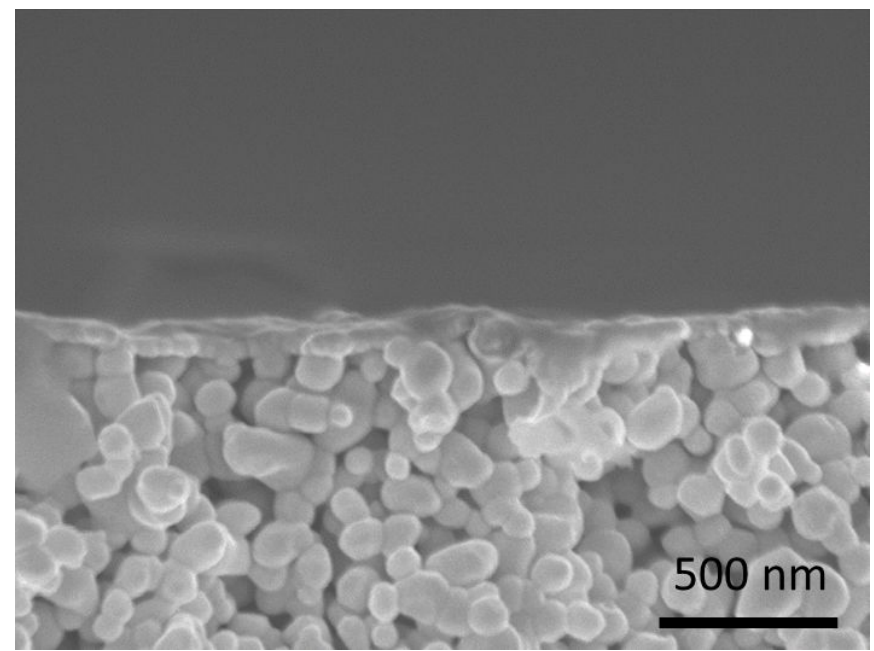

Figure S13. Cross-sectional SEM image of the TpEBr iCON membrane. 


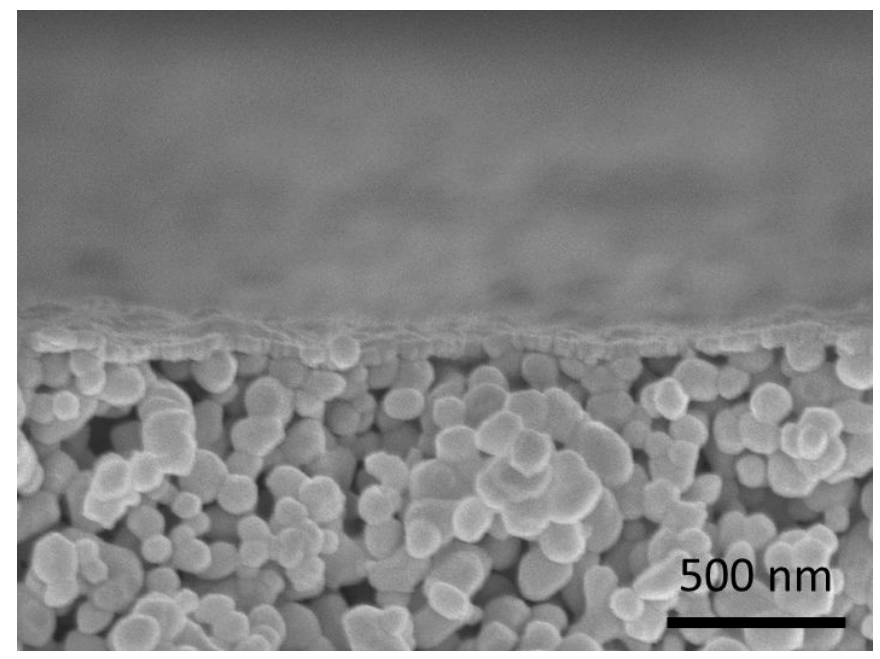

Figure S14. Cross-sectional SEM image of the $\mathrm{TpPa}-\mathrm{SO}_{3} \mathrm{Na}$ iCON membrane. 
Table S1. Single-component gas permeation data and ideal selectivity under 0.2 bar of transmembrane pressure difference at $423 \mathrm{~K}$.

\begin{tabular}{|c|c|c|c|c|c|c|c|}
\hline \multirow{2}{*}{ Membrane } & \multicolumn{4}{|c|}{ Permeability (Barrers) } & \multicolumn{3}{|c|}{ Ideal Selectivity } \\
\hline & $\mathrm{H}_{2}$ & $\mathrm{CO}_{2}$ & $\mathrm{~N}_{2}$ & $\mathrm{CH}_{4}$ & $\mathrm{H}_{2} / \mathrm{CO}_{2}$ & $\mathrm{H}_{2} / \mathrm{N}_{2}$ & $\mathrm{H}_{2} / \mathrm{CH}_{4}$ \\
\hline TpEBr@TpPa-SO $3 \mathrm{Na}$ & $107.77 \pm 8.61$ & $4.16 \pm 0.36$ & $2.69 \pm 0.24$ & $1.47 \pm 0.14$ & $26.2 \pm 2.1$ & $40.5 \pm 3.6$ & $74.2 \pm 6.9$ \\
\hline $\mathrm{TpEBr}$ & $143.28 \pm 12.92$ & $21.80 \pm 0.20$ & $15.31 \pm 0.13$ & $12.74 \pm 0.11$ & $6.5 \pm 0.5$ & $9.3 \pm 0.8$ & $11.1 \pm 1.0$ \\
\hline $\mathrm{TpPa} \mathrm{SO}_{3} \mathrm{Na}$ & $131.03 \pm 12.21$ & $16.29 \pm 0.14$ & $11.63 \pm 0.10$ & $10.53 \pm 0.90$ & $8.1 \pm 0.6$ & $11.4 \pm 1.0$ & $12.6 \pm 1.1$ \\
\hline
\end{tabular}




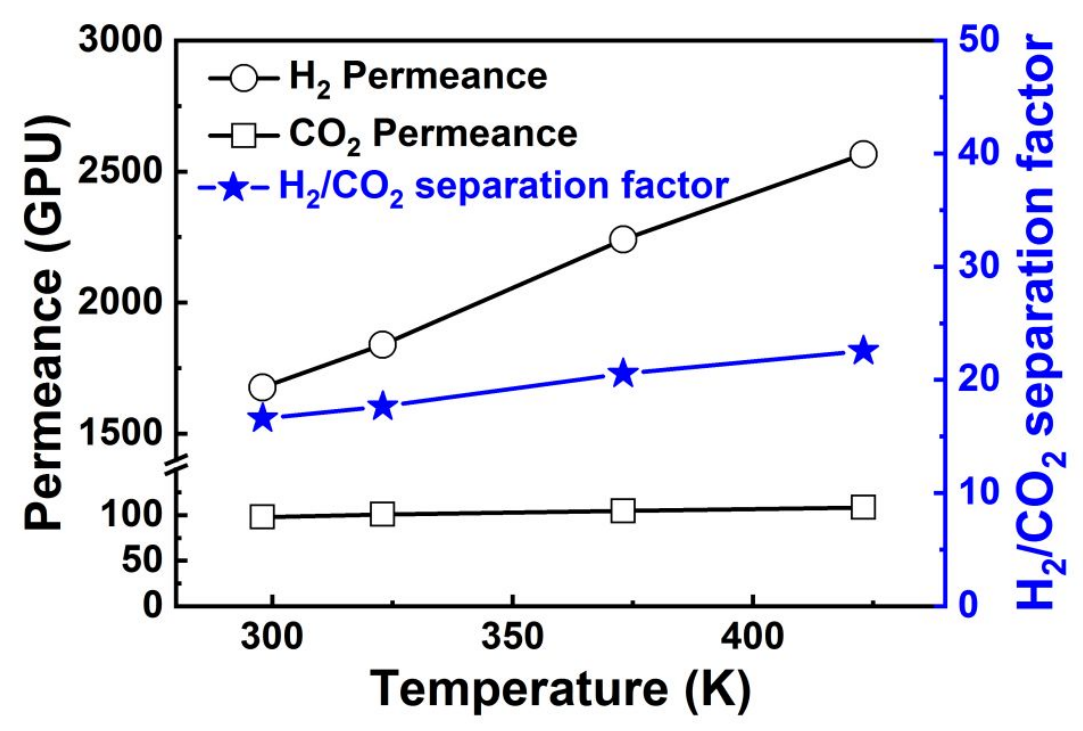

Figure S15. $\mathrm{H}_{2}$ permeance, $\mathrm{CO}_{2}$ permeance, and $\mathrm{H}_{2} / \mathrm{CO}_{2}$ separation factor of $\mathrm{TpEBr} @ T p P a-\mathrm{SO}_{3} \mathrm{Na}$ iCON membrane as a function of temperature under a transmembrane pressure of 0.2 bar. 


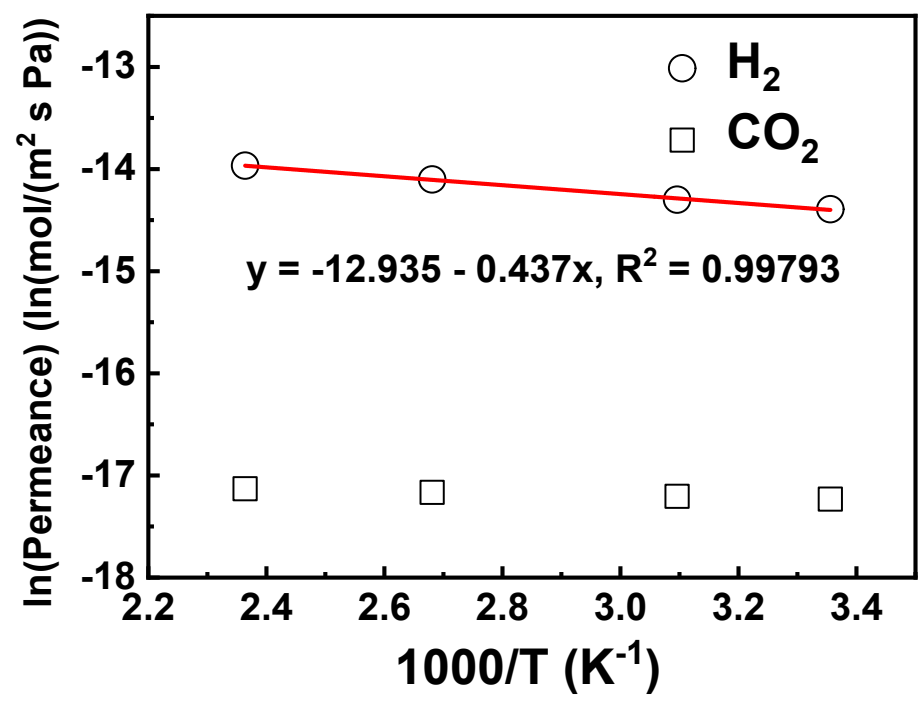

Figure S16. Arrhenius temperature dependence of $\mathrm{H}_{2}$ and $\mathrm{CO}_{2}$ permeance for $\mathrm{TpEBr} @ T p P a-\mathrm{SO}_{3} \mathrm{Na}$ iCON membrane.

Note:

The temperature dependence of gas permeation can be descripted by Arrhenius equations (equation S5 and S6):

$P_{i}=A_{i} \exp \left(-\frac{E_{a c t, i}}{R \cdot T}\right)$

$\ln \left(P_{i}\right)=\ln \left(A_{i}\right)-\frac{E_{a c t, i}}{R} \cdot \frac{1}{T}$

Eq. S6

where $P_{i}$ is the gas permeance (mol/ $\left.\left(\mathrm{m}^{-2} \mathrm{~s} \mathrm{~Pa}\right)\right)$ of component $i, A_{i}$ represents the pre-exponential factor of component $i, E_{a c t, i}$ is the apparent activation energy of component $i, R$ is the ideal gas constant $\left(8.314 \mathrm{~J} \cdot \mathrm{mol}^{-1} \cdot \mathrm{K}^{-}\right.$ $\left.{ }^{1}\right)$, and $T$ is the absolute temperature $(\mathrm{K})$. A plot of $\ln \left(P_{i}\right)$ versus $1 / T$ gives a straight line, whose slope is used to calculate $E_{a c t, i}$.

The apparent activation energy for $\mathrm{H}_{2}, E_{a c t, H 2}$, was calculated to be $3.63 \mathrm{~kJ} / \mathrm{mol}$. This indicates an activated diffusion process for $\mathrm{H}_{2}$ transport. Although the constant $\mathrm{CO}_{2}$ permeance suggests a weak temperature dependence, size exclusion would block the permeation of $\mathrm{CO}_{2}$ molecules. 

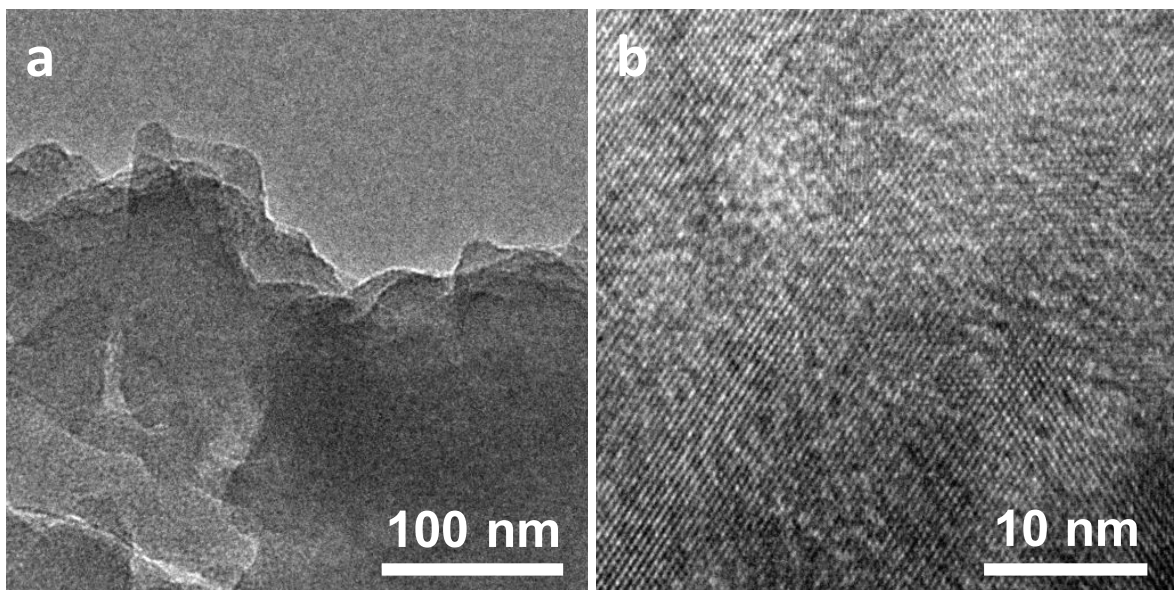

Figure S17. TEM images of the delaminated nanosheets from the membrane after being operated under wet feed gas condition: (a) low magnification, (b) high magnification. 


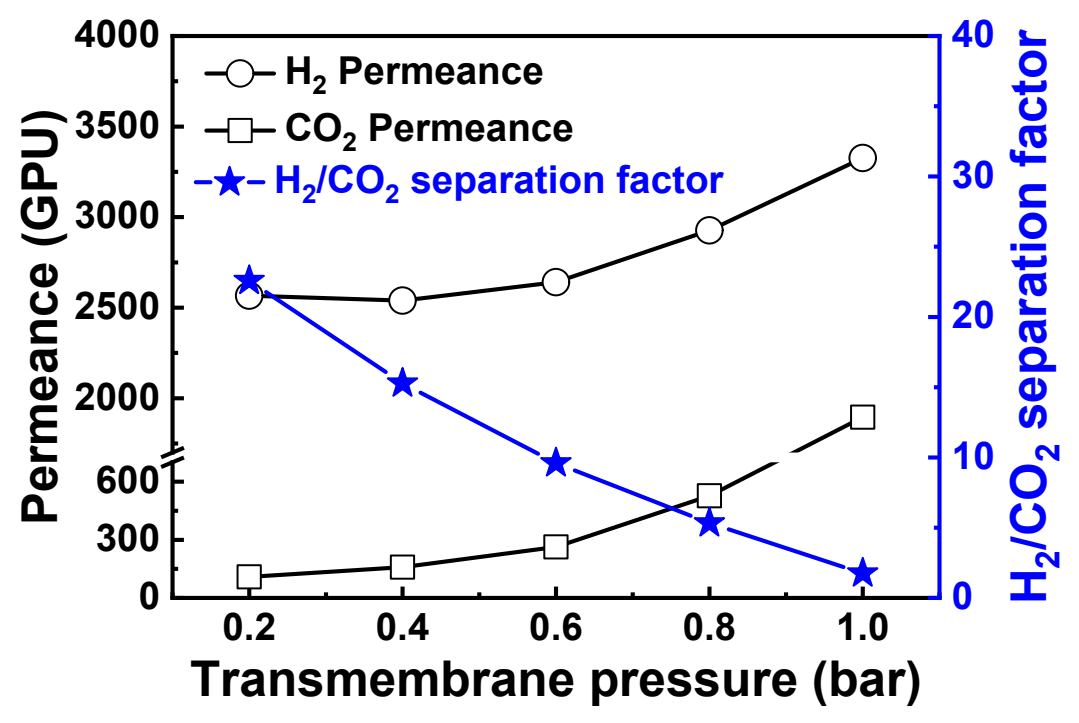

Figure S18. $\mathrm{H}_{2}$ permeance, $\mathrm{CO}_{2}$ permeance, and $\mathrm{H}_{2} / \mathrm{CO}_{2}$ separation factor of $\mathrm{TpEBr} @ \mathrm{TpPa}-\mathrm{SO} \mathrm{Na}_{3} \mathrm{iCON}$ membrane as a function of transmembrane pressure at $423 \mathrm{~K}$.

Note: We have actually tested our membranes under a transmembrane pressure of 0 at the initial stage of this project. The results are listed in Table S2. As has been mentioned in the manuscript, this membrane testing condition may have the risk of back flow of sweep gas, resulting in pseudo-selectivity that can be observed even in bare porous supports. From this table, we can clearly see that the iCON membrane has a much higher $\mathrm{H}_{2} / \mathrm{CO}_{2}$ separation factor when being tested under a transmembrane pressure of 0 , and even the bare support has a high $\mathrm{H}_{2} / \mathrm{CO}_{2}$ selectivity of 40 under the same testing condition. However, this is impossible as we could only observe at best Knudsen diffusion selectivity $\left(4.7\right.$ for $\mathrm{H}_{2} / \mathrm{CO}_{2}$ ) in the bare support given its large pore size (ca. $70 \mathrm{~nm}$ ), underlining the inaccuracy of this testing condition. In order to rule out the possibility of sweep gas back flow, an absolute pressure difference of 0.2 bar across the membrane (i.e., the feed pressure was fixed at 1.2 bar of absolute pressure and the sweep pressure was kept at 1 bar) was used in our home-built Wicke-Kallenbach gas permeation setup during this study except when studying the pressure effect. 
Table S2. Gas separation performance of iCON membrane under various transmembrane pressures.

\begin{tabular}{|c|c|c|c|c|c|c|}
\hline \multirow{2}{*}{$\begin{array}{c}\text { Transmembrane } \\
\text { Pressure (bar) }\end{array}$} & \multicolumn{2}{|c|}{$\mathbf{H}_{\mathbf{2}}$ Permeance (GPU) } & \multicolumn{2}{|c|}{$\mathbf{C O}_{\mathbf{2}}$ Permeance (GPU) } & \multicolumn{2}{c|}{$\mathbf{H}_{\mathbf{2}} / \mathbf{C O}_{2}$ Separation Factor } \\
\cline { 2 - 7 } & $\begin{array}{c}\text { Bare } \\
\text { Support }\end{array}$ & $\begin{array}{c}\text { iCON } \\
\text { Membrane }\end{array}$ & $\begin{array}{c}\text { Bare } \\
\text { Support }\end{array}$ & $\begin{array}{c}\text { iCON } \\
\text { Membrane }\end{array}$ & $\begin{array}{c}\text { Bare } \\
\text { Support }\end{array}$ & $\begin{array}{c}\text { iCON } \\
\text { Membrane }\end{array}$ \\
\hline 0 & 17,496 & $1,931.5$ & 367.4 & 8.8 & 40 & 214 \\
\hline 0.2 & 127,336 & 2,566 & 59,688 & 108.4 & 1.6 & 22.6 \\
\hline
\end{tabular}


Table S3. $\mathrm{H}_{2} / \mathrm{CO}_{2}$ separation performance in comparison to other membranes in the literature.

\begin{tabular}{|c|c|c|c|c|c|}
\hline Membrane & $\begin{array}{c}\text { Thickness } \\
\text { (nm) }\end{array}$ & $\begin{array}{c}\text { Permeance } \\
\text { (GPU) }\end{array}$ & $\begin{array}{c}\text { Permeability } \\
\text { (Barrers) }\end{array}$ & $\begin{array}{c}\text { Separation Factor } \\
\text { /Selectivity }\end{array}$ & Reference \\
\hline ZIF-8 & 6,000 & 471.9 & - & 4.6 & 5 \\
\hline ZIF-7 & 1,500 & 238.9 & - & 6.7 & 6 \\
\hline $\mathrm{NH}_{2}-\mathrm{MIL}-53$ (AI) & 15,000 & $5,928.9$ & - & 30.9 & 7 \\
\hline CAU-1 & 4,000 & 322.6 & - & 12.34 & 8 \\
\hline HKUST-1 & 60,000 & $6,332.1$ & - & 6.84 & 9 \\
\hline Zr-Anth-MOF & 1,000 & ca. 55 & & 26 & 10 \\
\hline ZIF-7-PBI & - & - & 26.2 & 14.9 & 11 \\
\hline ZIF-8@GO & 20,000 & 379.3 & - & 14.9 & 12 \\
\hline $\mathrm{Zn}_{2}(\mathrm{bim})_{4}$ & - & 2,700 & - & 291 & 13 \\
\hline MAMS-1 & 40 & 553 & - & 235 & 1 \\
\hline $2 \mathrm{H} \mathrm{MoS}_{2}$ & 500 & 2,350 & 1,175 & 8.29 & 14 \\
\hline GO & 9 & 298.7 & - & 3,400 & 15 \\
\hline EFDA-GO & 1,000 & 1,100 & 1,100 & 30 & 16 \\
\hline CTF-1@GO & 100 & $5,077.7$ & 507.8 & 17.4 & 17 \\
\hline [COF-300]-[ZIF-8] & 100,000 & 1,100 & 110,000 & 13.5 & 18 \\
\hline COF-LZU1-ACOF-1 & 1,000 & 731.8 & - & 24.2 & 19 \\
\hline BILP-101x & 400 & 24 & 9.6 & 40 & 20 \\
\hline TpEBr@TpPa-SO ${ }_{3} \mathrm{Na}$ & 41 & 2,566 & 105.2 & 22.6 & This work \\
\hline
\end{tabular}




\section{References}

1. Wang, X.; Chi, C.; Zhang, K.; Qian, Y.; Gupta, K. M.; Kang, Z.; Jiang, J.; Zhao, D. Reversed thermo-switchable molecular sieving membranes composed of two-dimensional metal-organic nanosheets for gas separation. Nat. Commun. 2017, 8, 14460.

2. Ma, H.; Liu, B.; Li, B.; Zhang, L.; Li, Y. G.; Tan, H. Q.; Zang, H. Y.; Zhu, G. Cationic Covalent Organic Frameworks: A Simple Platform of Anionic Exchange for Porosity Tuning and Proton Conduction. J. Am. Chem. Soc. 2016, 138 (18), 5897-5903.

3. Matsumoto, M.; Valentino, L.; Stiehl, G. M.; Balch, H. B.; Corcos, A. R.; Wang, F.; Ralph, D. C.; Mariñas, B. J.; Dichtel, W. R. Lewis-Acid-Catalyzed Interfacial Polymerization of Covalent Organic Framework Films. Chem 2018, 4 (2), 308-317.

4. Valentino, L.; Matsumoto, M.; Dichtel, W. R.; Marinas, B. J., Development and Performance Characterization of a Polyimine Covalent Organic Framework Thin-Film Composite Nanofiltration Membrane. Environ. Sci. Technol. 2017, 51 (24), 14352-14359.

5. Zhang, X.; Liu, Y.; Li, S.; Kong, L.; Liu, H.; Li, Y.; Han, W.; Yeung, K. L.; Zhu, W.; Yang, W.; Qiu, J. New Membrane Architecture with High Performance: ZIF-8 Membrane Supported on Vertically Aligned ZnO Nanorods for Gas Permeation and Separation. Chem. Mater. 2014, 26 (5), 1975-1981.

6. Li, Y. S.; Liang, F. Y.; Bux, H.; Feldhoff, A.; Yang, W. S.; Caro, J., Molecular sieve membrane: supported metalorganic framework with high hydrogen selectivity. Angew. Chem. Int. Ed. 2010, 49 (3), 548-551.

7. Zhang, F.; Zou, X.; Gao, X.; Fan, S.; Sun, F.; Ren, H.; Zhu, G. Hydrogen Selective NH2-MIL-53(Al) MOF Membranes with High Permeability. Adv. Funct. Mater. 2012, 22 (17), 3583-3590.

8. Zhou, S.; Zou, X.; Sun, F.; Ren, H.; Liu, J.; Zhang, F.; Zhao, N.; Zhu, G. Development of hydrogen-selective CAU1 MOF membranes for hydrogen purification by 'dual-metal-source' approach. Int. J. Hydrogen Energy 2013, 38 (13), 5338-5347.

9. Guo H.; Zhu G.; Hewitt I. J.; Qiu S. "Twin Copper Source" Growth of Metal-Organic Framework Membrane: $\mathrm{Cu}_{3}(\mathrm{BTC})_{2}$ with High Permeability and Selectivity for Recycling $\mathrm{H}_{2}$. J. Am. Chem. Soc. 2009, 131, 1646-1647.

10. Ghalei, B.; Wakimoto, K.; Wu, C. Y.; Pournaghshband Isfahani, A.; Yamamoto, T.; Sakurai, K.; Higuchi, M.; Chang, B. K.; Kitagawa, S.; Sivaniah, E. Rational Tuning of Zirconium Metal-Organic Framework Membranes for hydrogen purification. Angew. Chem. Int. Ed. 2019, 58 (52), 19034-19040.

11. Yang, T.; Xiao, Y.; Chung, T.-S. Poly-/metal-benzimidazole nano-composite membranes for hydrogen purification. Energy Environ. Sci. 2011, 4, 4171-4180.

12. Huang, A.; Liu, Q.; Wang, N.; Zhu, Y.; Caro, J. Bicontinuous zeolitic imidazolate framework ZIF-8@GO membrane with enhanced hydrogen selectivity. J. Am. Chem. Soc. 2014, 136 (42), 14686-14689.

13. Peng, Y.; Li, Y.; Ban, Y.; Jin, H.; Jiao, W.; Liu, X.; Yang, W. Metal-organic framework nanosheets as building blocks for molecular sieving membranes. Science 2014, 346 (6215), 1356-1359.

14. Achari, A.; S, S.; Eswaramoorthy, M. High performance $\mathrm{MoS}_{2}$ membranes: effects of thermally driven phase transition on $\mathrm{CO}_{2}$ separation efficiency. Energy Environ. Sci. 2016, 9 (4), 1224-1228. 
15. Li, H.; Song, Z.; Zhang, X.; Huang, Y.; Li, S.; Mao, Y.; Ploehn, H. J.; Bao, Y.; Yu, M. Ultrathin, molecular-sieving graphene oxide membranes for selective hydrogen separation. Science 2013, 342 (6154), 95-98.

16. Shen, J.; Liu, G.; Huang, K.; Chu, Z.; Jin, W.; Xu, N., Subnanometer Two-Dimensional Graphene Oxide Channels for Ultrafast Gas Sieving. ACS Nano 2016, 10 (3), 3398-3409.

17. Ying, Y.; Liu, D.; Ma, J.; Tong, M.; Zhang, W.; Huang, H.; Yang, Q.; Zhong, C. A GO-assisted method for the preparation of ultrathin covalent organic framework membranes for gas separation. J. Mater. Chem. A 2016, 4 (35), 13444-13449.

18. Fu, J.; Das, S.; Xing, G.; Ben, T.; Valtchev, V.; Qiu, S. Fabrication of COF-MOF Composite Membranes and Their Highly Selective Separation of $\mathrm{H}_{2} / \mathrm{CO}_{2}$. J. Am. Chem. Soc. 2016, 138 (24), 7673-7680.

19. Fan, H.; Mundstock, A.; Feldhoff, A.; Knebel, A.; Gu, J.; Meng, H.; Caro, J., Covalent Organic FrameworkCovalent Organic Framework Bilayer Membranes for Highly Selective Gas Separation. J. Am. Chem. Soc. 2018, 140 (32), 10094-10098.

20. Shan, M.; Liu, X.; Wang, X.; Yarulina, I.; Seoane, B.; Kapteijn, F.; Gascon, J. Facile manufacture of porous organic framework membranes for precombustion $\mathrm{CO}_{2}$ capture Sci. Adv. 2018, 4 (9), eaau1698. 